Trauma Surgery \& Acute Care Open

\title{
What are the strongest indicators of intracerebral hemorrhage in mild traumatic brain injury?
}

\author{
Panu Teeratakulpisarn, ${ }^{1}$ Phati Angkasith, ${ }^{1}$ Thanakorn Wannakul, ${ }^{1}$ Parichat Tanmit, ${ }^{1}$ \\ Supatcha Prasertcharoensuk, ${ }^{1}$ Chaiyut Thanapaisal, ${ }^{1}$ Narongchai Wongkonkitsin, ${ }^{1}$ \\ Amnat Kitkhuandee, ${ }^{1}$ Wattana Sukeepaisarnjaroen, ${ }^{2}$ Warinthorn Phuttharak, ${ }^{3}$ \\ Kittisak Sawanyawisuth (i) ${ }^{2}$
}

'Department of Surgery, Faculty of Medicine, Khon Kaen University, Khon Kaen, Thailand 2Department of Medicine, Faculty of Medicine, Khon Kaen University, Khon Kaen, Thailand ${ }^{3}$ Department of Radiology, Faculty of Medicine, Khon Kaen University, Khon Kaen, Thailand

\section{Correspondence to}

Professor Kittisak

Sawanyawisuth; kittisak@kku. ac.th

Dr Phati Angkasith; phati@ kku.ac.th

Received 11 February 2021 Accepted 19 July 2021 (c) Author(s) (or their employer(s)) 2021. Re-use permitted under CC BY-NC. No commercial re-use. See rights and permissions. Published by BMJ.

To cite: Teeratakulpisarn $\mathrm{P}$ Angkasith P, Wannakul T, et al. Trauma Surg Acute Care Open 2021:6:e000717.

\section{ABSTRACT}

Background Although there are eight factors known to indicate a high risk of intracranial hemorrhage $(\mathrm{ICH})$ in mild traumatic brain injury (TBI), identification of the strongest of these factors may optimize the utility of brain $\mathrm{CT}$ in clinical practice. This study aimed to evaluate the predictors of ICH based on baseline characteristics/ mode of injury, indications for brain CT, and a combination of both to determine the strongest indicator. Methods This was a descriptive, retrospective, analytical study. The inclusion criteria were diagnosis of mild TBI, high risk of ICH, and having undergone a CT scan of the brain. The outcome of the study was any type of ICH. Stepwise logistic regression analysis was used to find the strongest predictors according to three models: (1) injury pattern and baseline characteristics,

(2) indications for CT scan of the brain, and (3) a combination of models 1 and 2 .

Results There were 100 patients determined to be at risk of $\mathrm{ICH}$ based on indications for $\mathrm{CT}$ of the brain in patients with acute head injury. Of these, $24(24.00 \%)$ had ICH. Model 1 found that injury due to motor vehicle crash was a significant predictor of $\mathrm{ICH}$, with an adjusted OR $(95 \% \mathrm{Cl})$ of 11.53 (3.05 to 43.58). Models 2 and 3 showed Glasgow Coma Scale (GCS) score of 13 to 14 after 2 hours of observation and open skull or base of skull fracture to be independent predictors, with adjusted OR $(95 \% \mathrm{Cl})$ of $11.77(1.32$ to 104.96$)$ and $5.88(1.08$ to 31.99 ) according to model 2.

Discussion Open skull or base of skull fracture and GCS score of 13 to 14 after 2 hours of observation were the two strongest predictors of $\mathrm{ICH}$ in mild TBI. Level of evidence III.

\section{INTRODUCTION}

Traumatic brain injury (TBI) is a common problem in both developed and developing countries, with a worldwide incidence of 250 per 100000 persons per year. ${ }^{1}$ TBI incidence may vary by age, sex, and region. The incidence in young adults in France, for example, is 535 per 100000 persons, which is higher than in the USA (154) and Australia (240). The male to female ratio is generally about $2: 1$. Common causes of TBI include traffic-related injury, falls, or assault. ${ }^{1}$ It can lead to morbidity, mortality, and lack of well-being, particularly in the elderly, who are at greater risk of falls. ${ }^{2}$ In Thailand the rate of traffic-related injuries has been increasing, from 449.0 per 100000 population in 2012 to 524.9 in
2016, which may in turn result in similar increases in the incidence of TBI.

TBI can be classified into three categories: mild, moderate, or severe. ${ }^{4}$ Although mild TBI may result in lower morbidity, it causes cognitive impairment in $51.4 \%$ of cases and post-traumatic stress disorder in $18 \% .^{56} \mathrm{It}$ is important to accurately detect intracranial hemorrhage $(\mathrm{ICH})$, particularly in patients with mild TBI. However, to lower cost and avoid unnecessary radiation exposure, appropriate patient selection for CT of the brain is crucial. Several previous studies have reported predictors of intracranial bleeding in mild TBI. ${ }^{7-9}$ Some clinical factors predictive of ICH in mild TBI include headache, vomiting, and focal neurological deficit. ${ }^{10-12}$

In Thailand, a CT scan of the brain without contrast injection is indicated in patients with mild TBI identified as being at high risk of ICH. However, CT scans are only available at larger hospitals. Knowing the strongest predictors of ICH in patients with mild TBI may facilitate quick and appropriate case detection and reduce the risk of unnecessary radiation exposure, particularly in resource-limited settings such as community hospitals. Although there are eight factors that indicate a high risk of ICH in mild TBI, identification of the strongest of these factors may help optimize the utility of brain CT in clinical practice. This study aimed to evaluate the predictors of ICH based on baseline characteristics/injury-related factors, indications for brain CT, and a combination of the two to find the strongest indicator. Knowing these indicators may be helpful in triaging cases for CT, a potentially expensive tool with limited availability in developing countries or resource-limited settings.

\section{METHODS}

This was a descriptive, retrospective, analytical study and conducted at Khon Kaen University's Srinagarind Hospital in Thailand. The inclusion criteria were age $>18$ years, mild TBI, and high risk of ICH. All consecutive patients during the study period were admitted and underwent CT scans of the brain. Those with other abnormal CT findings, such as brain infarction, were excluded. Mild TBI was defined as Glasgow Coma Scale (GCS) score of 13 to 15 . Patients considered to be at high risk of ICH were those who exhibited any of the following: GCS score of 13 to 14 after 2 hours of observation, open skull or base of skull fracture, vomiting $>2$ 
episodes, focal neurological deficit, post-traumatic seizure, age 60 years or older, decrease in GCS score of more than 2 without identifiable causes, or high mechanism of injury. The study period was between January 1 and December 31, 2018.

Eligible patients' baseline characteristics, mechanism of injury, physical signs, and brain CT indications and results were recorded. Mechanisms of injury were categorized as fall, trafficrelated injury, or assault. Traffic-related injuries were classified by type of vehicles (car, motorcycle, bicycle, or pedestrian) and whether the patient was a driver or a passenger. Falls were classified as either same level or high. Place of injury was recorded as either home or road/park. History of alcohol consumption, history of loss of consciousness, and number of injury sites were also examined. The outcome of the study was any type of $\mathrm{ICH}$, including epidural hematoma, subdural hematoma, intracerebral hemorrhage, and subarachnoid hemorrhage. Outcomes were divided into two groups: $\mathrm{ICH}$ and non-ICH.

\section{Statistical analysis}

Descriptive statistics were used to calculate and compare differences in numerical and categorical factors between the ICH and non-ICH groups. Logistic regression analysis was used to find predictors of ICH. There were three models for ICH prediction: model 1, using injury pattern and baseline characteristics; model 2, using indications for brain CT; and model 3, which combined models 1 and 2 (using both injury pattern/baseline characteristics and indications for CT scan of the brain). Univariate logistic regression analysis was performed to determine the predictive strength of the studied factors. Factors with a $p$ value of less than 0.25 by the univariate logistic regression analysis were entered into a subsequent multivariate logistic regression model. Stepwise logistic regression analysis was executed for models 1 and 2 to find the strongest predictors. The remaining factors from those models were analyzed for the combination model. Results were reported as median (IQR), numbers (percentage), and unadjusted/adjusted OR with 95\% CI. Statistical analysis was computed using STATA V.10.1 (College Station, TX).

\section{RESULTS}

During the study period, there were 1268 patients with mild TBI, $117(9.23 \%)$ of whom were categorized as being at high risk of $\mathrm{ICH}$ (figure 1). Of these, 100 met the study criteria (17 patients were excluded as their TBI was due to brain infarction). ICH was found in 24 patients (24.00\%): 9 with subdural hematoma (37.5\%), 4 with subarachnoid hemorrhage $(16.7 \%)$, 4 with intracerebral hemorrhage (16.7\%), 2 with epidural hematoma $(8.2 \%)$, 4 with a combination of subdural hematoma and subarachnoid hemorrhage (16.7\%), and 1 with a combination of subdural hematoma and intracerebral hemorrhage (4.2\%).

Baseline characteristics and injury-related factors of eligible patients are shown in table 1 . There were three significant factors

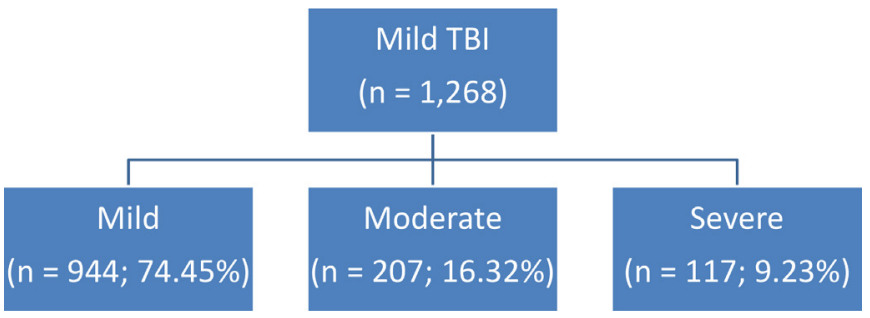

Figure 1 Study flow of patients with mild traumatic brain injury (TBI) during the study period categorized by severity of mild TBI.
Table 1 Baseline characteristics and injury-related factors in patients with acute head injury with suspected intracranial hemorrhage (ICH)

\begin{tabular}{|c|c|c|c|}
\hline Factors & $\begin{array}{l}\text { No ICH } \\
\mathrm{n}=76\end{array}$ & $\begin{array}{l}\text { ICH } \\
n=24\end{array}$ & $P$ value \\
\hline Median age (IQR) & $72(63-80)$ & $62(49-71)$ & 0.007 \\
\hline Male sex & $36(47.37)$ & $13(54.17)$ & 0.642 \\
\hline Mechanism of injury & & & $<0.001$ \\
\hline Fall & $57(77.03)$ & $7(29.17)$ & \\
\hline Traffic-related injury & $15(20.27)$ & $17(70.83)$ & \\
\hline Assault & $2(2.70)$ & 0 & \\
\hline \multicolumn{4}{|l|}{ Traffic-related injury } \\
\hline Type of vehicle & & & 0.469 \\
\hline Car & $4(26.67)$ & $2(11.76)$ & \\
\hline Motorcycle & $9(60.00)$ & $13(76.47)$ & \\
\hline Bicycle & $2(13.33)$ & $1(5.88)$ & \\
\hline Pedestrian & 0 & $1(5.88)$ & \\
\hline Driver/passenger & & & 0.394 \\
\hline Drivers & $11(68.75)$ & $13(86.67)$ & \\
\hline Passengers & $5(31.25)$ & $2(13.33)$ & \\
\hline Type of fall & & & 0.668 \\
\hline Same level & $43(74.14)$ & $7(87.50)$ & \\
\hline High fall & $15(25.86)$ & $1(12.50)$ & \\
\hline Place of injury & & & $<0.001$ \\
\hline Home & $58(76.32)$ & $7(29.17)$ & \\
\hline Road/park & $18(23.68)$ & $17(70.83)$ & \\
\hline Alcohol consumption & $8(10.53)$ & $5(20.83)$ & 0.293 \\
\hline History of loss of consciousness & $30(39.47)$ & $14(58.33)$ & 0.156 \\
\hline Multiple injuries & $11(14.47)$ & $8(3.33)$ & 0.069 \\
\hline
\end{tabular}

that differed between those with and without ICH: age, mechanism of injury, and place of injury. The ICH group had a lower median age (62 years vs. 72 years), higher proportion of traffic injuries $(70.83 \%$ vs. $20.27 \%)$, and higher proportion of road injuries $(70.83 \%$ vs. $23.68 \%)$ than the non-ICH group. There were two factors determined to be predictive of ICH according to model 1: involvement in a motor vehicle crash and multiple injuries (table 2). Of these, only motor vehicle crash involvement was significant, with an adjusted OR (95\% CI) of $11.53(3.05$ to 43.58 ) according to multivariate logistic regression analysis.

Among the eight indications for CT of the brain in patients with acute head injury, three differed significantly between those with and without ICH: GCS score of 13 to 14 after observation, open skull or base of skull fracture, and age 60 years or older (table 3). There were two significant predictors of $\mathrm{ICH}$ according to model 2: GCS score of 13 to 14 after 2 hours of observation and open skull or base of skull fracture, with adjusted OR (95\% CI) of 11.77 (1.32 to 104.96$)$ and 5.88 (1.08 to 31.99)

Table 2 Injury patterns and baseline characteristics (model 1) predictive of intracranial hemorrhage in patients with acute head injury remaining in the final model by stepwise analysis

\begin{tabular}{lll}
\hline Factors & Unadjusted OR (95\% Cl)* & Adjusted OR (95\% Cl)† \\
\hline $\begin{array}{l}\text { Motor vehicle } \\
\text { crash }\end{array}$ & $9.22(3.23$ to 26.31$)$ & $11.53(3.05$ to 43.58$)$ \\
\hline Multiple injuries & $2.95(1.02$ to 8.54$)$ & $1.98(0.64$ to 6.15$)$ \\
\hline
\end{tabular}

*Indicates univariate logistic regression analysis.

tIndicates multivariate logistic regression analysis. 


\begin{tabular}{|c|c|c|c|}
\hline Factors & $\begin{array}{l}\text { No ICH } \\
n=76\end{array}$ & $\begin{array}{l}\mathrm{ICH} \\
\mathrm{n}=24\end{array}$ & $P$ value \\
\hline $\begin{array}{l}\text { GCS score of 13-14 after 2-hour } \\
\text { observation }\end{array}$ & $1(1.32)$ & $5(20.83)$ & 0.003 \\
\hline Open skull or base of skull fracture & $2(2.63)$ & $5(20.83)$ & 0.008 \\
\hline Vomiting $>2$ episodes & $6(7.89)$ & 0 & 0.331 \\
\hline Focal neurological deficit & $1(1.32)$ & $1(4.76)$ & 0.391 \\
\hline Post-traumatic seizure & $1(1.33)$ & 0 & 0.999 \\
\hline Age $\geq 60$ years & $63(82.89)$ & $13(61.90)$ & 0.037 \\
\hline $\begin{array}{l}\text { Decrease in GCS score of more than } 2 \\
\text { without identifiable causes }\end{array}$ & 0 & 0 & NA \\
\hline High-energy trauma & $2(2.67)$ & 0 & 0.999 \\
\hline
\end{tabular}

GCS, Glasgow Coma Scale; NA, not available.

according to multivariate logistic regression analysis, as shown in table 4. In the combination model (model 3), only GCS score of 13 to 14 after 2 hours of observation and open skull or base of skull fracture remained significant. The adjusted OR $(95 \% \mathrm{CI})$ of these two factors was 18.10 (1.91 to 171.29) and 8.24 (1.33 to 50.75 ) according to multivariate logistic regression analysis (table 5).

\section{DISCUSSION}

Among the mechanisms of injury and baseline characteristics, only traffic-related injury was an independent factor for ICH. As previously reported, motor vehicle crashes are the most common cause of TBI in the USA, accounting for approximately $50 \%$ of cases. ${ }^{1}$ It is also a leading cause of TBI in developing countries. A report from India found that $56.3 \%$ of TBI cases were due to motor vehicle crash. ${ }^{10}$ Although several studies have reported on clinical factors predictive of ICH in mild TBI, ${ }^{911}$ none has found traffic-related injury to be a significant predictor. Our results may be explained by the high proportion of motor vehicle crash in our population (76.47\% in the ICH group), as shown in table 1 . We analyzed results by type of traffic injury and whether the patient was a passenger or a driver, but neither of these factors were statistically significant, with adjusted OR (95\% CI) of 0.71 (0.80 to 6.29) and 2.77 (0.34 to 22.27).

The most common indication in this study for CT scan of the brain was age $\geq 60$ years (76\%), as shown in table 3 . However, GCS score of 13 to 14 after 2 hours of observation and open skull or base of skull fracture were both strongly predictive after adjustment by other factors (table 4). A previous study found that if patients with mild TBI have GCS score of $15 / 15$, it may be safe to delay CT scanning of the brain for 8 hours. ${ }^{13}$ However, our study supported previous findings that GCS score of 13 or 14

Table 4 Indications for CT of the brain (model 2) predictive of intracranial hemorrhage in patients with acute head injury remaining in the final model by stepwise analysis

\begin{tabular}{lll}
\hline Factors & Unadjusted OR $(95 \% \mathrm{Cl})^{*}$ & Adjusted OR $(95 \% \mathrm{Cl}) \dagger$ \\
\hline $\begin{array}{l}\text { GCS score of } \\
\begin{array}{l}\text { 13-14 after 2-hour } \\
\text { observation }\end{array}\end{array}$ & $19.73(2.17$ to 179.06$)$ & $11.77(1.32$ to 104.96$)$ \\
$\begin{array}{l}\text { Open skull or base of } \\
\text { skull fracture }\end{array}$ & $9.73(1.75$ to 54.13$)$ & $5.88(1.08$ to 31.99$)$ \\
\hline
\end{tabular}

\footnotetext{
*Indicates univariate logistic regression analysis.

†Indicates multivariate logistic regression analysis.

GCS, Glasgow Coma Scale.
}

Table 5 Factors remaining in the final model predictive of intracranial hemorrhage in patients with acute head injury (model 3)

\begin{tabular}{lll}
\hline Factors & Unadjusted OR $(95 \% \mathrm{Cl})^{*}$ & Adjusted OR $(95 \% \mathrm{Cl}) \dagger$ \\
\hline Multiple injuries & $2.95(1.02$ to 8.54$)$ & $1.45(0.40$ to 5.24$)$ \\
\hline Motor vehicle crash & $9.22(3.23$ to 26.31$)$ & $1.98(0.88$ to 4.44$)$ \\
$\begin{array}{l}\text { GCS score of } 13-14 \text { after } \\
\text { 2-hour observation }\end{array}$ & $19.73(2.17$ to 179.06$)$ & $18.10(1.91$ to 171.29$)$ \\
$\begin{array}{l}\text { Open skull or base of skull } \\
\text { fracture }\end{array}$ & $9.73(1.75$ to 54.13$)$ & $8.24(1.33$ to 50.75$)$ \\
\hline
\end{tabular}

*Indicates univariate logistic regression analysis. †Indicates multivariate logistic regression analysis. GCS, Glasgow Coma Scale.

that does improve may be a strong indicator of ICH in patients with mild TBI (sensitivity of $83.3 \%$; table 3 ).${ }^{14}$ Skull fracture has also been reported as an indicator of $\mathrm{ICH}^{6}{ }^{6}$ We also found this to be the case, with a sensitivity of $71.4 \%$ (table 3 ).

After combining both models 1 and 2, clinical signs seemed to be stronger predictors of ICH than mechanism of injury (table 5). Both GCS score of 13 to 14 after 2 hours of observation and open skull or base of skull fracture were dominant factors in the multivariate analysis of the combination model. ${ }^{914}$ These results emphasize the importance of proper clinical examination by emergency room or trauma physicians to look for any skull or base of skull fracture as well as close monitoring of GCS during the first 2-hour period. Additionally, a previous study also found that GCS score of 13 predicted ICH with $100 \%$ sensitivity. ${ }^{15}$ This may justify performing brain CT in patients with mild TBI with GCS score of 13 to 14 without first waiting 2 hours.

Although age and involvement in a motor vehicle crash were significant factors according to descriptive statistics (table 1), the former did not remain and the latter was not significant in the final model (table 5). The median age of patients who had been in motor vehicle crash was significantly lower than those who had not $(58.5$ years vs. 74.5 years; $p<0.001)$. The fact that younger patients were more likely to have been involved in a motor vehicle crash likely accounts for the younger average age of patients in the ICH group versus the non-ICH group (62 years vs. 72 years; $p=0.007)$. The fact that involvement in a motor vehicle crash remained in the final model but not age (table 5) may indicate that mechanism of injury may be a more significant predictor of ICH than age but not when compared with the other two factors, as previously discussed.

Open skull or base of skull fracture and GCS score of 13 to 14 after 2 hours of observation were the two strongest predictors of ICH. Note that patients with GCS score of 13 to 14 may be eligible for a CT scan without the 2-hour wait. Other factors indicating a high risk of $\mathrm{ICH}$, such as vomiting $(0 \%)$ or post-traumatic seizure $(0 \%)$, were weaker predictors and/or less common in the ICH group (table 3). The results of this study may allow physicians at the emergency department to perform CT in mild TBI more rapidly and effectively. Additionally, physicians in resource-limited settings may be able to more accurately judge whether to transfer patients with mild TBI for brain CT. Note that the results of this study differ from those of previous studies in some respects. For example, one previous study found that $\mathrm{CT}$ can be safely delayed for up to 8 hours in patients with mild TBI and GCS score of $15,{ }^{8}$ whereas we suggest immediate brain CT if GCS score is 13 and 14 . Second, a previous report found high-energy trauma to be suggestive of ICH in mild TBI, whereas we did not. ${ }^{11}$ This difference may be due to the low prevalence of high-energy trauma in our study (two patients). 
Further prospective studies may be necessary to confirm our results prior to their implementation in clinical guidelines.

This study had some limitations. First, no methods of prevention or intervention, such as preventive models or encouraging the use of public transportation, were evaluated. ${ }^{16-19}$ Second, as this study was conducted in a university/tertiary hospital, the results may not be applicable to other settings. Another limitation was that some clinical factors that were not significant according to our model, such as age over 65 years combined with GCS score of 13, may be suggestive for brain CT in clinical practice. ${ }^{2021}$ Further studies are required to confirm our results. ${ }^{22}$ Additionally, some factors were not studied due to the retrospective design, including Injury Severity Score, coagulation factor, anticoagulant or antiplatelet therapy, and some laboratory tests such as serum ubiquitin C-terminal hydrolase L1. ${ }^{23-26}$ Finally, treatment and treatment outcomes were not reported.

\section{CONCLUSION}

Open skull or base of skull fracture and GCS score of 13 to 14 after 2 hours of observation were the two strongest predictors of ICH in mild TBI among the examined indicators for CT of the brain.

Acknowledgements We would like to thank the Khon Kaen University Research Center in Back, Neck, Other Joint Pain and Human Performance (BNOJPH), NorthEastern Stroke Research Group and the Faculty of Medicine Research Affairs Division (Khon Kaen, Thailand; MN63205), Khon Kaen University, Thailand.

Contributors PTe and PAn conceived and designed the study and defined the intellectual content. TWa, PTa, SPr, CTh, NWo, AKi, WPh, and PA performed the experiment and collected the data. WSu and KSa performed the statistical analysis and data interpretation. PTe and PAn drafted the article. All authors reviewed and approved the final draft of the article.

Funding The authors have not declared a specific grant for this research from any funding agency in the public, commercial or not-for-profit sectors.

Competing interests None declared.

Patient consent for publication Not required.

Ethics approval The Khon Kaen University institutional ethics board reviewed and approved this study with a waiver of informed consent due its retrospective nature (approval number HE611327).

Provenance and peer review Not commissioned; externally peer reviewed. Data availability statement Data are available upon reasonable request.

Open access This is an open access article distributed in accordance with the Creative Commons Attribution Non Commercial (CC BY-NC 4.0) license, which permits others to distribute, remix, adapt, build upon this work non-commercially, and license their derivative works on different terms, provided the original work is properly cited, appropriate credit is given, any changes made indicated, and the use is non-commercial. See: http://creativecommons.org/licenses/by-nc/4.0/.

ORCID iD

Kittisak Sawanyawisuth http://orcid.org/0000-0003-3570-8474

\section{REFERENCES}

1 Popescu C, Anghelescu A, Daia C, Onose G. Actual data on epidemiological evolution and prevention endeavours regarding traumatic brain injury. J Med Life 2015;8:272-7.

2 Jingmark S, Kuhirunyaratn P, Theeranut A, Nonjui P. Subjective well-being and related factors among community-dwelling elderly in Udon Thani Province, Thailand. Asia Pac J Sci Technol 2020;25:APST-25-01-09.

3 Suphanchaimat R, Sornsrivichai V, Limwattananon S, Thammawijaya P. Economic development and road traffic injuries and fatalities in Thailand: an application of spatial panel data analysis, 2012-2016. BMC Public Health 2019;19:1449.

4 Menon DK, Schwab K, Wright DW, Maas Al. Demographics and clinical assessment Working group of the International and Interagency initiative toward common data elements for research on traumatic brain injury and psychological health. position statement: definition of traumatic brain injury. Arch Phys Med Rehabil 2010;91:1637-40.

5 Delaplain PT, Albertson S, Grigorian A, Williams B, Smith M, Inaba K, Lekawa M, Nahmias J. Early cognitive impairment is common after intracranial hemorrhage with mild traumatic brain injury. J Trauma Acute Care Surg 2020;89:215-21.

6 Warren AM, Boals A, Elliott TR, Reynolds M, Weddle RJ, Holtz P, Trost Z, Foreman ML. Mild traumatic brain injury increases risk for the development of posttraumatic stress disorder. J Trauma Acute Care Surg 2015;79:1062-6.

7 Sharif-Alhoseini M, Khodadadi H, Chardoli M, Rahimi-Movaghar V. Indications for brain computed tomography scan after minor head injury. J Emerg Trauma Shock 2011:4:472-6.

8 Singata C, Candy S. Is computed tomography of the head justified in patients with minor head trauma presenting with Glasgow coma scale 15/15? SA J Radiol 2018;22:1329.

9 Saboori M, Ahmadi J, Farajzadegan Z. Indications for brain CT scan in patients with minor head injury. Clin Neurol Neurosurg 2007;109:399-405.

10 Ibañez J, Arikan F, Pedraza S, Sánchez E, Poca MA, Rodriguez D, Rubio E. Reliability of clinical guidelines in the detection of patients at risk following mild head injury: results of a prospective study. J Neurosurg 2004;100:825-34.

11 Molaei-Langroudi R, Alizadeh A, Kazemnejad-Leili E, Monsef-Kasmaie V, Moshirian $S$-Y. Evaluation of clinical criteria for performing brain CT-scan in patients with mild traumatic brain injury; a new diagnostic probe. Bull Emerg Trauma 2019;7:269-77.

12 Agrawal A, Galwankar S, Kapil V, Coronado V, Basavaraju SV, McGuire LC, Joshi R, Quazi SZ, Dwivedi S. Epidemiology and clinical characteristics of traumatic brain injuries in a rural setting in Maharashtra, India. 2007-2009. Int J Crit IIIn Inj SCi 2012;2:167-71.

13 Singata C, Candy S. Is computed tomography of the head justified in patients with minor head trauma presenting with Glasgow coma scale 15/15? SA J Radiol 2018;22:1329.

14 McCullagh S, Oucherlony D, Protzner A, Blair N, Feinstein A. Prediction of neuropsychiatric outcome following mild trauma brain injury: an examination of the Glasgow coma scale. Brain Inj 2001;15:489-97.

15 Yuksen C, Sittichanbuncha Y, Patumanond J, Muengtaweepongsa S, Aramvanitch K, Supamas A, Sawanyawisuth K. Clinical factors predictive for intracranial hemorrhage in mild head injury. Neurol Res Int 2017;2017:1-5.

16 Osakwe 0, Owoh UE, Oke SA. An accident prevention model: case study of a smallscale wood workshop in a developing country. Asia Pac J Sci Technol 2017;22:APST22-03-01.

17 Albertsson P, Falkmer T. Is there a pattern in European bus and coach incidents? A literature analysis with special focus on injury causation and injury mechanisms. Accid Anal Prev 2005;37:225-33.

18 Wongwiriya P, Nakamura F, Tanaka S, Miura S, Ariyoshi R. User perception of paratransit in Thailand: case study of traveling to work in Khon Kaen City. Asia Pac J Sci Technol 2017;22:APST-22-02-05.

19 Ohmori S, Yoshimoto K, Kuriyama S, Arunyanart S. Vehicle routing problem for freight forwarding. Asia Pac J Sci Technol 2017;22:APST-22-02-02.

20 Moore MM, Pasquale MD, Badellino M. Impact of age and anticoagulation: need for neurosurgical intervention in trauma patients with mild traumatic brain injury. $J$ Trauma Acute Care Surg 2012;73:126-30.

21 AbdelFattah KR, Eastman AL, Aldy KN, Wolf SE, Minei JP, Scott WW, Madden CJ, Rickert KL, Phelan HA. A prospective evaluation of the use of routine repeat cranial CT scans in patients with intracranial hemorrhage and GCS score of 13 to 15. J Trauma Acute Care Surg 2012;73:685-8

22 Rapp PE, Curley KC. Is a diagnosis of "mild traumatic brain injury" a category mistake? J Trauma Acute Care Surg 2012;73:S13-23.

23 Papa L, Lewis LM, Silvestri S, Falk JL, Giordano P, Brophy GM, Demery JA, Liu MC, Mo J, Akinyi L, et al. Serum levels of ubiquitin C-terminal hydrolase distinguish mild traumatic brain injury from trauma controls and are elevated in mild and moderate traumatic brain injury patients with intracranial lesions and neurosurgical intervention. J Trauma Acute Care Surg 2012;72:1335-44.

24 Barbosa RR, Jawa R, Watters JM, Knight JC, Kerwin AJ, Winston ES, Barraco RD, Tucker B, Bardes JM, Rowell SE, et al. Evaluation and management of mild traumatic brain injury: an eastern association for the surgery of trauma practice management guideline. J Trauma Acute Care Surg 2012;73:S307-14.

25 Stone ME, Safadjou S, Farber B, Velazco N, Man J, Reddy SH, Todor R, Teperman S. Utility of the military acute concussion evaluation as a screening tool for mild traumatic brain injury in a civilian trauma population. J Trauma Acute Care Surg 2015;79:147-51

26 von der Brelie C, Schneegans I, van den Boom L, Meier U, Hedderich J, Lemcke J. Impaired coagulation is a risk factor for clinical and radiologic deterioration in patients with traumatic brain injury and isolated traumatic subarachnoid hemorrhage. J Trauma Acute Care Surg 2015;79:295-300. 